\title{
Hepatitis por citomegalovirus: Presentación de dos casos
}

\author{
Cytomegalovirus hepatitis: Report of two cases.
}

\author{
Tori Carlos ${ }^{1}$, Leon Barua Raúl ${ }^{2}$, Roe Carlos ${ }^{3}$. \\ ${ }^{1}$ Pediatra. Clínica Médica Ambulatoria. Universidad Peruana Cayetano Heredia y Clínica \\ San Felipe. \\ ${ }^{2}$ Profesor Principal. Departamento de Medicina, Universidad Peruana Cayetano Heredia. \\ ${ }^{3}$ Clínica San Felipe.
}

\section{SUMMARY}

Two cases of hepatitis by cytomegalovirus are described, one in a child and the other in a young adult, presenting with a history of fever, general malaise, hepatomegaly and no jaundice. Their blood test showed atypical lymphocytes, normal bilirubin, elevated liver enzymes, and IgG antibodies against cytomegalovirus. Their course was un was unremarkable except for asthenia which persisted in spite of clinical and laboratory improvement. This course was unremarkable except for asthenia which persisted in spite of clinical and laboratory improvement. This presentation is done because of the low prevalence or infrequent diagnosis of anicteric hepatitis due to cytomegalovirus in normal individuals. Most of the literature refers to congenital cases, premature babies, or patients with debilitating or immunocompromising diseases.

KEY WORDS: Cytomegalovirus, hepatitis, anicteric.

\section{INTRODUCCION}

En nuestro medio, la hepatitis por citomegalovirus (CMV) es poco prevalente o infrecuentemente diagnosticada.

En el presente artículo describimos dos casos de ese proceso que hemos visto recientemente.

\section{Caso 1}

D.T.M. de 11 años de edad y sexo femenino. Fue vista por primera vez el 18 de noviembre de 1994. Desde 11 días antes de la consulta había tenido escalofríos, fiebre con temperatura de hasta $38^{\circ} \mathrm{C}$, sudoración, cansancio, anorexia, y disfonía. Al examen clínico se encontró hepatomegalia, con hígado palpable a $4.5 \mathrm{~cm}$ por debajo del reborde costal. Exámenes auxiliares. Hemogramas: Hematíes 4’370,000 y leucocitos $11,100 / \mathrm{mm}^{3}$; abastonados $1 \%$, 
segmentados $23 \%$, linfocitos $74 \%$, monocitos $2 \%$ linfocitos atípicos "virales" $3 \%$;

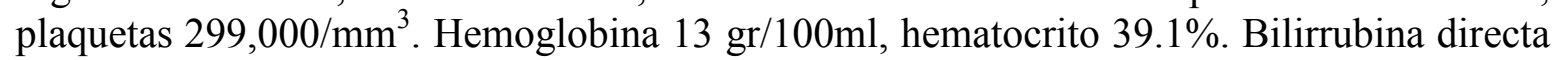
$0.3 \mathrm{gr} / 100 \mathrm{ml}$, bilirrubina total $0.5 \mathrm{mg} / 100 \mathrm{ml}$. Transaminasa GP $702 \mathrm{UI} / \mathrm{L}$, transaminass GO $381 \mathrm{UI} / \mathrm{L}$. Gammaglutamiltranspeptidasa $26.6 \mathrm{UI} / \mathrm{ml}$; fosfatasa alcalina $114.1 \mathrm{UI} / \mathrm{I}$ (15-60; niños 20-150). Marcadores serológicos para hepatitis A, B y C ausentes. Aglutinaciones negativas. Anticuerpos a virus de Epstein-Barr $94.8 \mathrm{u} / \mathrm{ml}$ (0.09, negativo; 91-99, indefinido; $>99$ positivo). Anticuerpos (IgM) a CMV $103.2 \mathrm{u} / \mathrm{ml}$ (0-30, negativo; 30-40, indefinido; $>40$ positivo); anticuerpo ( $\mathrm{IgG}$ ) a CMV $190.9 \mathrm{U} / \mathrm{ml}$ (0-18 negativo; 18-23, indefinido; > 23 positivo); los anticuerpos a CMV fueron investigados empleando una técnica de ELISA semiautorizada. Examen de orina negativo. Evolución: Se le indicó reposo.

Continuó con fiebre leve y sudoración, cansado y anorexia. A los 6 días de la primera consulta, la hepatomegalia persistía, aunque la transaminasa GP había descendido a 291 $\mathrm{UI} / \mathrm{L}$ y la GO a $106 \mathrm{UI} / 1$. A los 17 días de la hepatomegalia se había reducido a $2.5 \mathrm{cms}, \mathrm{y}$ las transaminasas habían vuelto casi a sus niveles normales; sin embargo, el cansancio y la anorexia persistía. Recibió sólo antipiréticos.

\section{Caso 2}

A.G.N.B., de 21 años de edad y sexo femenino, estudiante universitaria. Fue vista por primera vez el 14 de noviembre de 1994. Desde dos semanas antes de la consulta había tenido malestar general, cansancio, cefalea, fiebre con temperatura de hasta $38.2^{\circ} \mathrm{C}$, tos seca, sensación de distención epigástrica postprandial, náusea y meteorismo. El examen clínico fue esencialmente negativo.

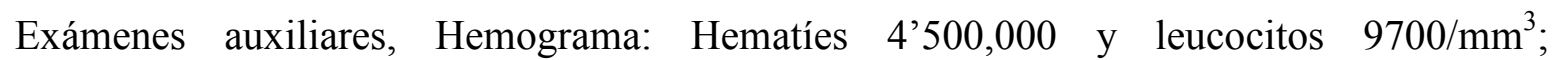
abastonados $6 \%$, segmentados $12 \%$, linfocitos $80 \%$ y monocitos $2 \%$; linfocitos atípicos "virales" $15 \%$ plaquetas $190,000 / \mathrm{mm}^{3}$. Hemoglobina $12.2 \mathrm{gr} / 100 \mathrm{ml}$, hematocrito $37.8 \%$. Velocidad de sedimentación $20 \mathrm{~mm} / \mathrm{hr}$. Bilirrubina directa $0.20 \mathrm{mg} / 100 \mathrm{ml}$. Bilirrubina total $0.60 \mathrm{mg} / 100 \mathrm{ml}$. transaminasa GP $554 \mathrm{UI} / \mathrm{l}$, transaminasa GO $428 \mathrm{UI} / \mathrm{L}$. Marcadores serológicos para hepatitis viral de tipo A, B y C ausentes. Aglutinaciones negativas. Monotest negativo. Anticuerpos (IgM) a CMV 42.1 U/ml (0-30, indefinido; $>40$ positivo, iniciando infección actual o reciente). Examen de orina negativo. Radiografía de tórax negativa.

Evolución. Desde el 15 de noviembre la temperatura disminuyó a $37.5^{\circ} \mathrm{C}$. Se le indicó reposo y ácido ascórbico $500 \mathrm{mg}$. antes del desayuno y cena. El 28 de noviembre los linfocitos en la fórmula sanguínea habían descendido a 50\%, la transaminasa GP a 40 UI/1 y la GO a $20 \mathrm{UI} / \mathrm{L}$.

E1 5 de diciembre la temperatura continuaba en $37.8^{\circ} \mathrm{C}$, los linfocitos habían descendido a $43 \%$, y las transaminasas eran normales. 


\section{DISCUSIÓN}

Las infecciones por CMV son causadas generalmente por la variedad humana del microorganismo y raramente por la simiana (1). En individuos infectados el virus está presente en saliva, partes del aparato respiratorio, leche materna, cerviz uterino, orina, heces, leucocitos y diversos tejidos (2). La transmisión puede efectuarse por contacto directo entre personas, especialmente sexual, al feto y al niño durante la gestación, el parto o la lactancia, y por transfusiones de sangre o trasplantes de órganos $(1,2)$. La transmisión en la casa o en guarderías infantiles ha sido bien documentada (1).

El período de incubación para infecciones por contacto directo es desconocido. Sin embargo, se sabe que las primeras manifestaciones aparecen de 3 semanas a 3 meses después de una transfusión sanguínea, y de 4 semanas a 4 meses después de un año de transplante (1). Después de una primo-infección, el proceso puede permanecer en estado durante varios años, reactivándose sólo en condiciones de inmunosupresión (1).

La infección por CMV es generalmente asintomático; $\mathrm{y}$, cuando no lo es, sus manifestaciones varían con la edad y el grado de inmunocompetencia del receptor (2).

Alrededor de un 5\% de recién nacidos infectados presentan retardo de crecimiento intrauterino, ictericia, púrpura, hepatoesplenomegalia, microcefalia, daño cerebral, calcificaciones intracerebrales y corioretinitis $(1,2)$.

En individuos inmunocomprometidos, sobre todo con SIDA, el CMV, en especial cuando se asocia con Pneumocystis carinii, ocasiona frecuentemente neumonitis intersticial (2).

Los individuos pueden presentar también retinitis con pérdida de visión y síntomas gastrointestinales como son disfagia, sensación de llenura epigástrica, dolor abdominal, diarrea y hasta hemorragias gastrointestinales (2).

Se ha descrito asimismo casos de aplasia de médula ósea similares a los originados por otros virus, entre ellos, el parvovirus B19, del dengue, de la hepatitis, de Epstein-Barr y del SIDA (4).

Cuando la infección se adquiere en la infancia o en la niñez, puede presentarse en forma de neumonía, ya sea bronquial o intersticial, erupción cutánea petequial, diarrea o hepatitis con discreta hepatomegalia (2). En estas edades, el CMV raramente da lugar a meningoencefalitis polineuritis o coriorretinitis (2).

En niños mayores o adultos, sin inmunodeficiencia, como nuestros pacientes, el CMV puede producir un cuadro parecido al de la mononucleosis, pero con ausencia de reacción serológica indicativa de esta enfermedad (2). Los hallazgos clínicos son malestar general, fatiga, mialgias, cefaleas, anorexia, dolor abdominal, hepatoesplenomegalia y resultados anormales de función hepática (2). Adultos jóvenes presentan hepatitis con fiebre prolongada y linfocitos atípicos "virales". 
Un cuadro de este tipo sugiere en primer lugar las posibilidades de hepatitis viral de tipo A, $\mathrm{B}$ o no A-no $\mathrm{B}(\mathrm{C})$, o mononucleosis. Antes de advenimiento de técnicas adecuadas para investigar la presencia de anticuerpos a CMV, si los marcadores serológicos para hepatitis y mononucleosis estaban ausentes se hacía el diagnóstico de "virosis" o de "compromiso hepático por virus" no definidos. En la actualidad, contándose ya con técnicas apropiadas para diagnosticar rápidamente la presencia de CMV, esta posibilidad debe tenerse siempre en cuenta para lograr un diagnóstico correcto, como ocurrió en los casos que hemos presentado.

\section{Correspondencia}

Dr. Carlos Tori

Centro Médico San Felipe.

Av. Gregorio Escobedo 660

Jesús María

Lima - Perú.

\section{REFERENCIAS BIBLIOGRAFICAS}

1.American Academy of Pediatrics. Summaries of infectous diseases. En: Peter G (ed). Red Book : Report of the Committee on Infectious Diseases. 23 rd ed. Elk Grove Village, II: American Academy of Pediatrics; 1994: 173-7.

2.Medearis D Jr. Citomegalovirus. En: Kliegman B.(eds): Textbook of pediatrics. 14 th ed. Philadelphia: WB. Saunders, 1992: 514-6, 803-5, 819.

3.Carey WD, Patel G. Viral hepatitis in the 1990s, Part III: Hepatitis C, hepatitis E, and other viruses. Cleve Clin J Med 1992; 59: 595-601.

4.Rosenfeld SJ, Young NS. Viruses and bone marrow. Blood Rev 1991; 5: 71-7. 